\title{
Measuring Spirituality as a Universal Human Experience: A Review of Spirituality Questionnaires
}

\author{
Eltica de Jager Meezenbroek • Bert Garssen • \\ Machteld van den Berg • Dirk van Dierendonck • \\ Adriaan Visser • Wilmar B. Schaufeli
}

Published online: 20 July 2010

(C) The Author(s) 2010. This article is published with open access at Springerlink.com

\begin{abstract}
Spirituality is an important theme in health research, since a spiritual orientation can help people to cope with the consequences of a serious disease. Knowledge on the role of spirituality is, however, limited, as most research is based on measures of religiosity rather than spirituality. A questionnaire that transcends specific beliefs is a prerequisite for quantifying the importance of spirituality among people who adhere to a religion or none at all. In this review, we discuss ten questionnaires that address spirituality as a universal human experience. Questionnaires are evaluated with regard to psychometric properties, item formulation and confusion with well-being and distress. Although none of the questionnaires fulfilled all the criteria, the multidimensional Spiritual Well-Being Questionnaire is promising.
\end{abstract}

Keywords Spirituality - Connectedness · Transcendence - Questionnaires · Review

\section{Introduction}

The relationship between spirituality and health has received increasing attention in recent decades; the rate of publications on spirituality and health has increased by $688 \%$ in the last 30 years (Weaver et al. 2006). Many people experience spirituality as an important support aid while trying to cope with a chronic or life-threatening disease (Stefanek et al. 2005). Spiritual orientation has been shown to be associated with mental health (Sawatzky

E. de Jager Meezenbroek $(\bowtie) \cdot$ B. Garssen · M. van den Berg · A. Visser

Helen Dowling Institute, Care for Cancer, Rubenslaan 190, 3582 JJ Utrecht, The Netherlands e-mail: e.dejager@hdi.nl

D. van Dierendonck

Department of Organization and Personnel Management, Rotterdam School of Management, Erasmus University Rotterdam, Rotterdam, The Netherlands

W. B. Schaufeli

Department of Psychology, Utrecht University, Utrecht, The Netherlands 
et al. 2005; Koenig et al. 2001), and the association is especially strong among people facing stressful life events, such as a chronic or life-threatening disease (Smith et al. 2003).

Nevertheless, knowledge on the role of spirituality among patients and their caregivers is in a certain sense limited, as most research is based on measures of religiosity rather than spirituality (George et al. 2000; Baldacchino and Draper 2001). These religiosity questionnaires rely predominantly on monotheistic terminology inquiring, for example, about belief in God or experience of God (MacDonald et al. 1995). Such questionnaires may be appropriate in North America, where $83 \%$ of inhabitants consider God as highly important in their lives (Carballo 1999). However, this type of questionnaire would not be suitable in Western Europe, where only $49 \%$ of inhabitants consider God as highly important (Carballo 1999). Although many people in Western Europe do not believe in God, many people are interested in spirituality. Books and magazines on personal growth, meaning and spirituality, for example, are popular, as are publications on practicing meditation or yoga. Both religious and non-religious people could have spiritual experiences in which they are, for example, deeply touched by nature or cultural expression. A questionnaire that transcends specific beliefs, therefore, is a prerequisite for quantifying the importance of spirituality among people who adhere to a religion or no religion at all. In this review, we focussed on spirituality questionnaires that are suitable for a broad group of people with various religious or secular backgrounds and questionnaires that consider spirituality as a universal human experience.

Spirituality scales have already been described in several reviews (e.g. Hill and Hood 1999; MacDonald et al. 1999a, b; Shorkey et al. 2007; King and Crowther 2004). However, most reviews discuss only a few spirituality questionnaires without a religious focus, which in itself warrants a new review. The reviews by MacDonald et al. (1995, 1999a, b) discuss several spirituality questionnaires that transcend a specific religion, but although MacDonald et al. pay attention to the persistent flaw that most questionnaires are based on the Jewish and Christian traditions, they do not systematically evaluate the questionnaires in relation to the viewpoints of these traditions. In addition, reviews do not discuss the formulation of the items. In scale construction, the formulation of items is important; items should be comprehensible, have a consistent meaning and answerable by all respondents (Fowler 1995). Spirituality is often described in vague terms, and it is therefore important to check whether the items are comprehensible and have a consistent meaning. Finally, most reviews neglect the inclusion of well-being items, which we consider to be another flaw in some questionnaires. For nursing and health research, it would certainly be interesting to investigate whether a spiritual attitude is associated with well-being, but to prevent tautology, a questionnaire on spirituality should not question itself about well-being (Koenig et al. 2001).

In the present review, we focussed on spirituality questionnaires that are suitable for both religious and non-religious people. We excluded questionnaires with too many religious or belief items. Because spirituality has a religious component for people adhering to a faith, questionnaires were allowed to have a maximum of one religious subscale.

In the following part of the article, we will first define spirituality, next we will describe the method of instrument selection, followed by criteria for the evaluation of the instruments. We will then discuss the spirituality questionnaires with respect to the following three themes: psychometric properties, item formulation and confusion with well-being and distress. We will discuss separately one- or two-dimensional questionnaires and multidimensional questionnaires. Depending on the specificity of the research question, a researcher will be more interested in the first type of questionnaires, which are global measures of spirituality, or the second type of questionnaires, which delineate the different elements of spirituality. 


\section{Defining Spirituality}

Spirituality is a complex multidimensional concept (Cook 2004; Hill et al. 2000; George et al. 2000; Moberg 2002). The concept defies clear-cut boundaries, which also applies to other latent constructs that are often used, such as character, well-being and health (Miller and Thoresen 2003). Many definitions of spirituality have been proposed from different disciplines and perspectives. For example, spirituality has been described as "the way in which people understand and live their lives in view of their ultimate meaning and value" (Muldoon and King 1995), p. 336), as "a subjective experience of the sacred" (Vaughan 1991, p. 105), and as "a quality that goes beyond religious affiliation, that strives for inspirations, reverence, awe, meaning and purpose, even in those who do not believe in any good." (Murray and Zenter 1989). It seems almost impossible to find a description with which the majority of people would agree. Zinnbauer et al. (1999) described five studies in which various groups of people were asked to define spirituality. They concluded that differences in the responses of the participants outweighed by far the similarities. McSherry and Cash (2004) even stated that we should accept that the word 'spirituality' has different meanings.

Our approach in this review has been to use a comprehensive definition that covers several dimensions. The advantage of a broad definition is that it could be used to formulate various facets of spirituality. Empirical research could then assess the validity of the theoretically proposed facets, which would contribute to the clarification of the concept. We looked for a definition of spirituality that reflects the experiences of people from different religious or secular backgrounds and that reflects current (western) culture, where many people are searching for profundity and meaning in life on the basis of personal experiences and insight, instead of on the basis of external rules, norms and expectations (Heelas 2005). In current (western) culture, more and more people are searching for a connection with the divine within themselves, instead of a connection with an external almighty power (Heelas 2000).

In view of this, we have defined spirituality as one's striving for and experience of connection with oneself, connectedness with others and nature and connectedness with the transcendent. Conceptual analyses (Dyson et al. 1997; Cook 2004; Chiu et al. 2004; Reed 1992) and qualitative research (Hungelmann et al. 1985; Fisher 1998, cited in Gomez and Fisher 2003) have shown that connectedness is an essential element of spirituality. Furthermore, several authors, who approach spirituality as a universal human experience, define spirituality in terms of connectedness or relatedness. For example, the National Interfaith Coalition on Aging (1975) described spiritual well-being as the affirmation of life in a relationship with self, community, environment and God. This working definition emerged from several meetings with representatives from various religions. In nursing research, spirituality is also often defined in terms of connectedness. Reed (1992) defined spirituality on the basis of conceptual, empirical and clinical nursing literature as "the propensity to make meaning through a sense of relatedness to dimensions that transcend the self in such a way that empowers and does not devalue the individual. This relatedness may be experienced intrapersonally (as a connectedness within oneself), interpersonally (in the context of others and the natural environment) and transpersonally (referring to a sense of relatedness to the unseen, God, or power greater than the self and ordinary source)" (Reed 1992, p 350).

Connectedness encompasses various aspects that can play a role in every human. Connectedness with oneself is expressed by aspects such as authenticity, inner harmony/ inner peace, consciousness, self-knowledge and experiencing and searching for meaning in 
life (Elkins et al. 1988; Young-Eisendrath and Miller 2000; Hungelmann et al. 1985; Howden 1992; Mahoney and Graci 1999; Chiu et al. 2004). Connectedness with others and with nature is related to compassion, caring, gratitude and wonder. Connectedness with the transcendent includes connectedness with something or someone beyond the human level, such as the universe, transcendent reality, a higher power or God. Aspects related to this last theme are awe, hope, sacredness, adoration of the transcendent and transcendental experiences (Cook 2004).

\section{Methods}

Articles on spirituality were collected by searching for "spiritual*' in the title, abstract and keywords from the last 10 years, using Current Contents for the Behavioral Sciences (1998-2008). Relevant, new references found in these articles were also tracked. In addition, we searched for "questionnaire", "scale" or "inventory" in combination with "spirit*", "transcendent*", "transperson*" or "connectedness" in the title of articles, using Web of Science (Science Citation Index Expanded, Social Sciences Citation Index Arts and Humanities Citation Index). Over eight hundred articles were collected. One hundred and twenty of these articles reported on the development or validity of spirituality questionnaires, including 12 reviews (Egbert et al. 2004; Hill and Hood 1999; King and Crowther 2004; MacDonald et al. 1995, 1999a, b; Shorkey et al. 2007; Tuck et al. 2001; Stanard et al. 2000; Lukoff et al. 1993; Garssen et al. 2001; Hill 2005). The total number of questionnaires covered by these 120 articles exceeds well over 120, as some reviews report about numerous questionnaires. MacDonald et al., for example, mention 76 questionnaires and they already excluded questionnaires focusing on religion (MacDonald et al. 1995, 1999a, b).

As it is hardly practical to discuss all the available questionnaires on spirituality, their number was limited by selecting questionnaires with the following properties: (a) suitability to a broad group of people with various religious or secular backgrounds, (b) having a broad scope and (c) at least some psychometric data have been published.

We used the following criteria to define whether a questionnaire is suitable to a broad group of people: to be suitable for non-religious individuals, a questionnaire should consist of at least one non-religious subscale and no more than one religious subscale. A religious subscale was defined as a scale containing more than $25 \%$ items about religion or belief. An item was considered to refer to religion if it contained one or more words such as "religiosity" or "faith" or words referring to a religious person such as "God" or "Mohammed" or to religious customs or objects such as "praying" or "synagogue". Unless, these words were presented as an example and were combined with non-religious examples, such as: "How long have you been making use of an activity for obtaining inner peace (e.g. meditation, yoga, prayer etc.)?" (Mental, Physical and Spiritual well-being scale; Vella-Brodrick and Allen 1995). To be suitable for people with various backgrounds, the items of a questionnaire should also not inquire about a specific belief, such as belief in afterlife, witchcraft, or destiny. Items inquiring about opinions relating to values in one's personal life were allowed. Questionnaires that are only suited to one specific group were also omitted; for example, we did not include the Spirituality Transcendence Measure (Leung et al. 2006), because it is only suited to terminal patients. It includes questions such as "Fulfill last wishes with the assistance of family or professional caregivers". We did, however, include questionnaires that were originally developed for a specific group but had also been used effectively among various groups, such as the Self-Transcendence Scale (Reed 1991), which was developed for elderly people. 
Having a broad scope was operationalized as addressing at least two of the three connectedness themes (connectedness with oneself, the environment and the transcendent).

Finally, we used the criterion that at least data about either internal consistency or factor structure should have been published.

The inclusion criteria were applied to all spirituality questionnaires that were mentioned in the 120 articles (including the 13 reviews). Ten questionnaires fulfilled our inclusion criteria and were included in this review. Additional information on all questionnaires was looked for by searching under the name of the questionnaire in Web of Science.

The spirituality questionnaires will be discussed in relation to the following three themes: psychometric properties, item formulation and confusion with well-being and distress.

The first theme concerns psychometric properties, namely (a) reliability (internal consistency), (b) factorial validity and (c) convergent validity. The following criteria were used: (a) Cronbach's $\alpha \geq .70$; (b) Factor analytic confirmation of the clustering of items into subscales, as based on theoretical assumptions or earlier factor analytic findings; (c) Moderate or strong associations ( $r \geq .30$; Cohen 1988) with other spirituality measures. Subscales that measure transcendental aspects are moderately or strongly associated $(r \geq .30)$ with religiosity measures. We will also report about other psychometric aspects, namely other forms of convergent validity (such as the relationship between the subscales of a questionnaire), discriminant validity and normal distribution of scale scores. Formal criteria were not used, because information about these aspects was often lacking or provided in a different manner. When information was available about these psychometric aspects, we mentioned it in the text, but we did not use it to compare the instruments with each other.

To evaluate the formulation of the items, we determined whether the items are comprehensible, have a consistent meaning and are answerable by all respondents. To evaluate this, we used the following three criteria of Fowler (1995): (a) Items should inquire about firsthand experiences and not about, for example, hypothetical behavior or about causality; (b) items include a single question, questions should, for example, not include hidden contingencies; and (c) items have to be formulated such that they have a consistent meaning; therefore, words have to be used which are generally understandable and have the same meaning for respondents. Words that have different meanings to respondents should be either omitted or explained. Because people have different understandings of the words "spirit", "spiritual" or "spirituality", such words should be omitted or explained in the questions. More than $75 \%$ of the items should fulfill all three criteria.

The last theme concerns confusion with well-being and distress. Items should not ask directly about positive or negative affect, because this will artificially inflate the relationship between spirituality and well-being (less than $25 \%$ of the items).

\section{One- or Two-dimensional Spirituality Questionnaires}

\section{Evaluation Results}

Four spirituality questionnaires consisted of one or two subscales. Each questionnaire was evaluated according to eight criteria. The results are presented in Table 1. The following text elucidates the evaluation results and includes additional information. All questionnaires were developed in the USA, unless stated otherwise. 
Table 1 Evaluation of one- or two-dimensional spirituality questionnaires

\begin{tabular}{|c|c|c|c|c|c|c|}
\hline & \multicolumn{4}{|c|}{ Psychometric qualities } & \multirow{2}{*}{ 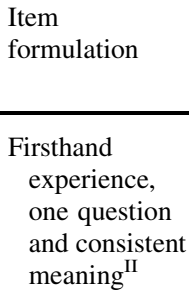 } & \multirow{2}{*}{$\begin{array}{l}\begin{array}{l}\text { Confusion } \\
\text { with well- } \\
\text { being }\end{array} \\
\begin{array}{l}\text { No reference } \\
\text { in wording } \\
\text { of items to } \\
\text { affect }^{\text {II }}\end{array}\end{array}$} \\
\hline $\begin{array}{l}\text { Questionnaire } \\
\text { (no. of } \\
\text { scales, no. of } \\
\text { items) }\end{array}$ & $\begin{array}{l}\text { Internal } \\
\text { consistency }\end{array}$ & $\begin{array}{l}\text { Factor } \\
\text { structure } \\
\text { confirmed }\end{array}$ & $\begin{array}{l}\text { Positive } \\
\text { association } \\
\text { with } \\
\text { spirituality } \\
\text { measures }^{I}\end{array}$ & $\begin{array}{l}\text { Positive } \\
\text { association } \\
\text { with } \\
\text { religiosity } \\
\text { measures, a }\end{array}$ & & \\
\hline $\begin{array}{l}\text { FACIT-sp12 } \\
(2,12)\end{array}$ & + & +- & $\begin{array}{l}+ \text { Faith } \\
\pm \text { Meaning/ } \\
\text { peace }\end{array}$ & $\begin{array}{l}+ \text { Faith } \\
\text { - Meaning/ } \\
\text { peace }\end{array}$ & - & - \\
\hline $\begin{array}{l}\text { MPS spirit. } \\
\text { subscale (1, } \\
10)\end{array}$ & + & $?$ & + & $?$ & + & + \\
\hline STS $(1,15)$ & + & $?$ & + & + & + & - \\
\hline SWB $(2,20)$ & + & - & + & $\begin{array}{l}+ \text { RWB } \\
- \text { EWB }\end{array}$ & - & - \\
\hline
\end{tabular}

$?=$ no data available; $+=$ criterion is met; $+-=$ criterion is sometimes met; $-=$ criterion is not met

${ }^{\text {I }}$ Criterion: $|r|>.30$; ${ }^{\text {II }}$ Criterion: more than $75 \%$ of the items

${ }^{\text {a }}$ Only subscales measuring connectedness with the transcendent are expected to meet the criterion

\section{Spiritual Well-Being Scale of the Functional Assessment of Chronic Illness Therapy (FACIT-Sp-12; Brady et al. 1999)}

This is a module of a Quality of Life (QOL) assessment instrument for chronically ill people. It was developed with input from patients with cancer, psychotherapists and religious/spiritual experts, who were asked to describe aspects of spirituality that contribute to QOL. It was designed to measure several aspects of spirituality such as sense of meaning in life, peacefulness and sense of strength and comfort from one's faith. The instrument consists of two subscales based on factor analytic findings (Peterman et al. 2002): Meaning/Peace and Faith. A newer, extended version consists of three subscales with 23 items instead of 12 items. We will discuss the 12-item instrument, as most studies used this version and because it has been tested more extensively. This instrument is used frequently and is available in various languages: www.facit.org.

Psychometric Qualities The factor structure is somewhat doubtful. Although Peterman et al. (2002) found three factors, a two-factor solution appeared to be more interpretable. Nevertheless, three items loaded on both factors. The two-factor solution of the Japanese version of the instrument even revealed that ten of the twelve items loaded on both factors, which showed that the two-factor structure was doubtful for this Japanese sample (Noguchi et al. 2004). Convergent validity was demonstrated for the Faith subscale, as it was associated with spirituality and religiosity measures and with purpose in life (Peterman et al. 2002; Riley et al. 1998). Mixed findings about convergent validity were reported for the Meaning/Peace subscale (Peterman et al. 2002; Noguchi et al. 2006). The Faith subscale appeared to be skewed (Brady et al. 1999). 
Item Formulation None of the items of the Faith subscale fulfilled our criteria. All items include hidden contingencies as they assume that the respondent adheres to a faith or spiritual beliefs (e.g. "I find comfort in my faith or spiritual beliefs") or suffers from an illness.

Confusion with Well-Being The questionnaire was developed as a (spiritual) well-being scale. The Faith subscale asks about the comfort and strength that is derived from the respondent's faith, instead of asking only about strength of faith. Due to this ambiguous content, this subscale should not be used for determining a relationship with well-being. Unsurprisingly, the subscale Meaning/Peace asks about aspects which are considered to be related to well-being. This subscale could be used, provided researchers are clear about the content of the measure.

\section{Spirituality Subscale of the Mental, Physical and Spiritual Well-being Scale} (MPS, Vella-Brodrick and Allen 1995)

The Australian MPS was designed to measure mental, physical and spiritual well-being. It was developed by starting with a large item pool, which was reduced and adjusted in several studies on the basis of feedback on the items, limited response variance and factor analyses. Our evaluation is based on the 10-item spiritual subscale. A limitation of this questionnaire is that it has a narrow focus because almost all questions describe activities, such as the use of meditation or prayer, and discussing spiritual, ethical or moral topics with other people.

Psychometric Qualities The MPS was developed on the basis of two-factor analyses which yielded three factors concurring with the three well-being domains. Thirty items were chosen: for each well-being domain, the ten items with the highest factor loadings were selected. In a new study, an exploratory factor analysis again yielded three factors, but six items did not load as expected (Vella-Brodrick and Allen 1995). The MPS correctly predicted membership of three activity groups (chess, weight training and prayer) and was associated with a spirituality questionnaire (Vella-Brodrick and Allen 1995). The MPS was not related to social desirability (Vellabrodrick and White 1997).

Item Formulation Many items include the words "spirit" or "spiritual". Most items, however, fulfill our criteria, because these words were explained. For example, in the item "Do you discuss matters of the spirit (e.g. purpose in life, religion, inner peace, death etc.)?"

Confusion with Well-Being Although the name of the subscale leads one to suspect that the items include well-being, this is mostly not the case.

\section{Self-Transcendence Scale (STS, Reed 1991)}

The STS was developed for elderly people and measures self-transcendence. Self-transcendence was defined as "the expansion of one's conceptual boundaries inwardly through introspective activities, outwardly through concerns about others' welfare, and temporally by integrating perceptions of one's past and future to enhance the present" (Reed 1991), p. 50). The unidimensional scale includes spiritual experiences and attitudes such as sharing wisdom, helping others, finding meaning and acceptance. 
Psychometric Qualities The reliability of the STS appeared acceptable, except in one study $(\alpha=.52$; Chin and Fernsler 1998). The STS was associated with sense of coherence, purpose in life, spirituality and religiousness (Wasner et al. 2005; Nygren et al. 2005; Coward 1996; Ellermann and Reed 2001).

Item Formulation Most items fulfill our criteria. Some items refer to old age or disease, such as "Adjusting to the changes in my physical abilities" or "Accepting myself as I grow older”.

Confusion with Well-Being This instrument includes some well-being items that refer to adjustment and enjoying hobbies.

\section{Spiritual Well-being Scale (SWB; Ellison 1983)}

This well-being questionnaire has been applied in many studies and extensively tested, especially in nursing research. It includes two subscales: the Existential Well-Being (EWB) scale, which assesses the "horizontal" dimension referring to a sense of purpose in life and life satisfaction, and the Religious Well-Being (RWB) subscale, which assesses the "vertical" dimension referring to a sense of well-being in relation to God.

Psychometric Qualities Convergent validity was shown as EWB was associated with purpose in life (Ellison 1983) and hope (Carson et al. 1990) and RWB with purpose in life and intrinsic religiosity (Ellison 1983). However, the factor analytic characteristics of the SWB were insufficient. Some evidence was found for the original solution (Miller et al. 1998), but in several studies, the original two-factor solution could not be confirmed (Miller et al. 1998; Matheis et al. 2006; Ledbetter et al. 1991; Scott et al. 1998; Ledbetter et al. 1991a, b; Scott et al. 1998). The EWB scale was affected by socially desirable responses (Ellis and Smith 1991). The SWB also showed ceiling effects in religious samples (Ledbetter et al. 1991b).

Item Formulation The RWB scale includes conditional items since belief in God is assumed.

Confusion with Well-Being Many items of the SWB ask about positive affect, for example: "I feel that life is a positive experience" or "My relationship with God contributes to my sense of well-being". Therefore, using the SWB as a predictor for wellbeing is not recommended.

\section{Discussion}

Researchers who want to use a short global measure of spirituality and do not feel the need to differentiate between various spirituality aspects could choose between the four scales discussed in the previous section.

Most questionnaires were reliable and showed convergent validity. However, information on factorial validity was either lacking (MPS spirituality subscale and the STS) or not confirmed (FACIT-sp12 and SWB). A reason for the unclear factor structure of the FACIT-sp12 and the SWB could be the inclusion of well-being items in the two subscales of these questionnaires. As a result, the two subscales of both questionnaires might cluster 
together in factor analyses, as in the study of Noguchi et al. (2004), where a two-factor solution of the items of the FACIT-sp12 showed that ten items loaded on both factors.

The MPS spirituality subscale and the STS contain well-formulated items. The FACITsp12 and the SWB include a scale assuming that the respondent has a certain belief. If a researcher wants to study the relationship between spirituality and well-being/distress, the spirituality subscale of the MPS is recommended. Too many well-being items are included in the other three questionnaires. A limitation of the MPS spirituality subscale is its focus on activities.

In summary, all one-dimensional or two-dimensional questionnaires have limitations and the adequacy of the questionnaires depends on the research question.

\section{Multidimensional Questionnaires}

Evaluation Results

Six multidimensional spirituality questionnaires will be briefly discussed in alphabetical order (see also Table 2). All questionnaires were developed in the USA, unless stated otherwise.

\section{Prague Spirituality Questionnaire (PSQ; Rican and Janosova 2005)}

This Czech questionnaire was developed to measure spirituality "common to individuals of different religions, even to people rejecting religion as such". The researchers took over and/or adapted items from the Mysticism Scale (Hood 1975), the Spiritual Transcendence Scale (STS, Piedmont 1999) and the Expressions of Spirituality Inventory (MacDonald 2000). In a pilot study, a preliminary version of the questionnaire was psychometrically analyzed. On the basis of interviews with college students and the psychometric analyses, the questionnaire was adjusted and new items were formulated to broaden the content of the instrument. Next, the questionnaire was psychometrically studied in a student population. A factor analysis yielded five factors: Mysticism (transcendental experiences), Togetherness, Transcendental-Monotheistic Experience (connectedness with the universe, the "highest reality" and beliefs about death), Eco-spirituality (connectedness with nature) and Moral Involvement. The last two scales are specific for this questionnaire. The authors themselves query the factor Moral Involvement. From interviews, it appeared that most elements of this factor felt old-fashioned and of little meaning to the young generation. The content of this factor seems also questionable, as all items express a negative self-image, like fear of spoiling one's life and shame of one's own cowardice.

Psychometric Qualities The only psychometric information that the authors (Rican and Janosova 2005) have provided is a factor analysis solution, which appeared reasonable.

Item Formulation Many items have an inconsistent meaning and might appear vague or odd to some respondents, such as "The death means returning "home" and "I have had an experience that I looked into the depth of being". Other items are difficult to answer because they include multiple questions, for example "I have experienced that face to face a rock or a mountain I felt their sacred mission, and I had a desire to get to know them". 


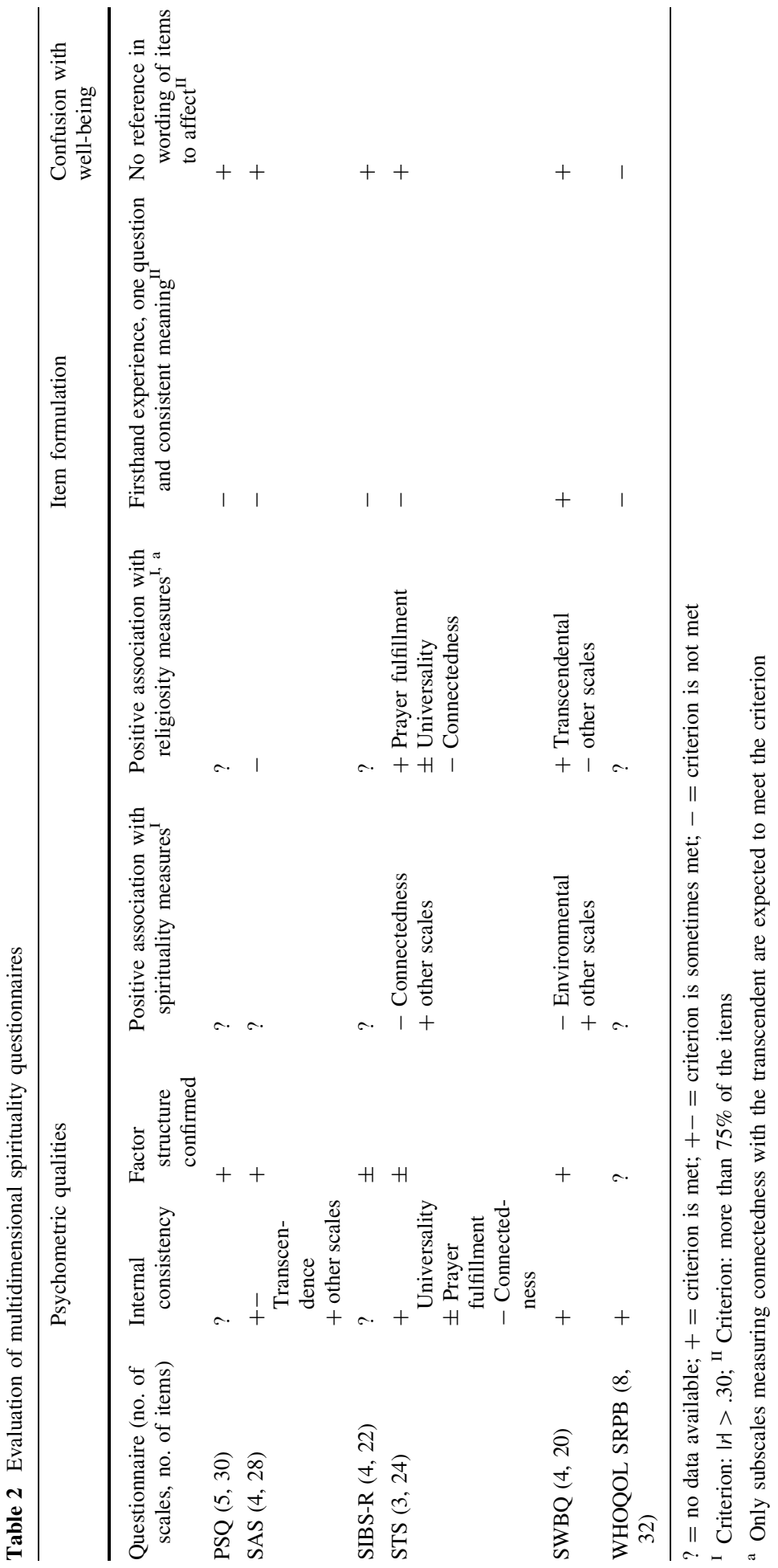


Confusion with Well-Being No reference to positive or negative affect.

Spirituality Assessment Scale (SAS; Howden 1992)

Howden (1992) developed the SAS by reviewing philosophical, psychological, sociological, theological and nursing literature. The following four scales of the SAS were developed on the basis of a literature review: Purpose and Meaning in Life, Interconnectedness (connectedness to others and to the environment), Innerness (inner peace and inner strength in times of difficulties) and Transcendence.

Psychometric Qualities Howden (1992) demonstrated satisfactory internal consistency of the four scales. MacDonald (2000) also found acceptable internal consistency for the subscales, except for the Transcendence scale (the exact Cronbach's $\alpha$ was not given). A factor analysis globally supported the theoretical division into four dimensions. However, it appeared more conducive to subdivide the two scales Interconnectedness and Innerness, each into two subscales (Howden 1992). Information on convergent and discriminant validity is lacking.

Item Formulation The formulation of several items is inappropriate. An example is "I have the ability to rise above or go beyond a physical or psychological condition". The question does not ask about firsthand experience, is not restricted to a single question and probably has an inconsistent meaning because of the figurative language and abstract concepts. Other examples are "The meaning I have found for my life provides a sense of peace" and "The boundaries of my universe extend beyond usual ideas of what space and time are thought to be".

Confusion with Well-Being The questionnaire does not ask about negative or positive feelings.

Spiritual Involvement and Beliefs Scale Revised Version (SIBS-R; R. L. Hatch, personal communication, July 27, 2007; SIBS: Hatch et al. 1998)

The SIBS was developed by identifying fifteen aspects of spirituality. Input was obtained from individuals who adhere to a religion and from individuals attending Alcoholics Anonymous. The questionnaire was substantially revised because of concern about the wording of certain items and the concern that the scale lacked certain domains of spirituality (R.L. Hatch, personal communication, July 27, 2007). The revised version was investigated in three samples. Based on these findings, the SIBS was again revised resulting in the SIBS-R. Factor analyses resulted in four factors: Core Spirituality (among others meaning, faith and spiritual activities), Spiritual Perspective/Existential (meaning, connectedness with nature, gratitude and morality), Personal Application/humility and Acceptance/insight. The conceptual basis of the scales is unclear as the first two scales reflect many different aspects and the last two consist only of two and one item, respectively.

Psychometric Qualities Psychometric validation of the SIBS-R is preliminary. The final version of the instrument was only factor-analyzed in samples which were used to develop the instrument. Two items loaded on two factors and five items had low factor loadings. 
Other psychometric information is only available for the total scale (R. L. Hatch, personal communication, July 27, 2007; Hyland et al. 2007).

Item Formulation The word "spiritual" appears in many items, for example in the item "I solve my problems without using spiritual resources". Also several items do not inquire about firsthand experiences, such as the item "My relationship with a higher power helps me love others more completely".

Confusion with Well-Being No reference to positive or negative affect.

\section{Spiritual Transcendence Scale (STS; Piedmont 1999)}

Starting point in the development of this questionnaire was the discussions among a consortium of experts from various faith traditions who identified common aspects of spirituality. Three scales were formed on the basis of explorative factor analyses: Prayer fulfillment (a feeling of joy and contentment that results from prayer and/or meditation), Universality (a belief in the unity and purpose of life) and Connectedness (a sense of personal responsibility and commitment to others) (Piedmont 1999).

Psychometric Qualities The STS has been studied intensively. Both exploratory and confirmative factor analyses found support for the three-factor structure (Piedmont 1999), though in one study among Indian students, sufficient support was only found for two of the three factors (Piedmont and Leach 2002). The distribution of items into the three scales is also conceptually unconvincing. For instance, items about the belief in or experience of the next world are also found in the second scale ("I believe that death is a doorway to another plane of existence") as well as in the third scale ("Although dead, images of some relatives continue to influence my current life"). In addition, the internal consistency of the Connectedness scale was insufficient $\alpha=.23$ to .65 (Bartlett et al. 2003; Piedmont 1999, 2001, 2004; Piedmont and Leach 2002; Leach and Lark 2004). Convergent validity could not be demonstrated for this scale either. Factorial independence of the three STS scales from the Big Five Factors of personality was shown. A validity test, unique for this questionnaire, is the comparison between self-report and observer ratings on the same dimensions. There appeared to be a close relationship between how spiritual a person considers himself and how an acquaintance assessed the subject's level of spirituality $r=.38$ to .55 (Piedmont 1999, 2001).

Item Formulation Many items include words that are probably unclear or repelling to some people such as "I have had at least one 'peak' experience" and "I believe that death is a doorway to another plane of existence".

Confusion with Well-Being No reference to positive or negative affect.

Spiritual Well-Being Questionnaire (SWBQ, Gomez and Fisher 2003)

The recently developed Australian SWBQ questionnaire is based on the definition of the National Interfaith Coalition on Aging (NICA), which states "the affirmation of life in a relationship with oneself (personal), others (communal), nature (environment), and God (or transcendental other)" (Gomez and Fisher 2003, p. 1976). Using the four domains as a 
framework, approximately one hundred secondary school teachers were interviewed about what they thought were important indicators of spiritual well-being in their students. The interviews used questions derived from a number of measures of spiritual well-being. The interviews supported the above-mentioned four domains that were used as a basis for the SWBQ. The SWBQ consists of a personal, communal, environmental and transcendental well-being scale, each consisting of five items. The four domains are hypothesized to be subsumed by a second-order global spiritual well-being dimension.

Psychometric Qualities This scale has been investigated thoroughly, particularly with respect to the factor structure of the instrument. In three student samples, explorative and confirmatory factor analyses confirmed the subdivision into four subscales and a secondorder factor analysis confirmed the single higher-order factor (Gomez and Fisher 2003). In addition, a multi-group confirmatory factor analysis largely supported gender equivalencies of the measurement (Gomez and Fisher 2005b). Convergent and discriminant validity (factorial independence from personality domains and social desirability) were largely supported. Finally, in addition to traditional psychometric analyses, item response theory analysis was applied (Gomez and Fisher 2005a). There were indications that some items could be further improved. Although the instrument has been investigated in detail, all studies used students from secondary schools and/or university. The validity of the instrument for a population sample is still to be investigated.

Item Formulation The items are very short and probably easy to understand for many people. However, we have a doubt about the interpretability of the questions. Respondents are asked to answer how they feel each item reflects their personal experience. All items ask about developing an attitude or experience, for example: "Developing respect for others". Theoretically, people who are respectful and people with little respect, but who are trying to develop it, could both give the same answer. Also, "developing" does not seem the proper verb in the following items "Developing trust between individuals" and "Developing a sense of "magic" in the environment".

Confusion with Well-Being Only one item asks directly about well-being, namely the item "developing joy in life".

WHOQOL Spirituality, Religion and Personal Beliefs (WHOQOL SRPB; O'Connell et al. 2006)

The WHOQOL SRPB is based on the WHOQOL-100, which is a generic quality of life instrument. The development of the WHOQOL SRPB followed the WHOQOL methodology in which centers from several countries collaborated and used a common protocol (WHOQOL Group 1996). International experts suggested facets related to spirituality. Focus groups in fifteen countries reviewed the importance of the facets and suggested items. A questionnaire with fifteen facets resulted. Next, eight facets were selected on the basis of inter-item correlations and factor analysis. The WHOQOL SRPB consists of the following facets: Connectedness to a Spiritual Being or Force, Meaning of Life, Awe, Wholeness and Integration (an integration of "mind, body and soul"), Spiritual Strength, Inner Peace/Serenity/harmony, Hope and Optimism and Faith. 
Psychometric Qualities The selection of eight facets was made in one large sample $(n=5,087)$ in 18 countries (O'Connell et al. 2006). All psychometric data come from the same sample. Explorative factor analysis on a random split half-sample confirmed the eight-factor solution. An explorative factor analysis using all the facets of the WHOQOL100 and of the WHOQOL SRPB revealed a six-factor solution. All SRPB facets loaded on one factor providing preliminary evidence that the SRPB facets form an independent domain that is distinct from other domains of quality of life.

Item Formulation Many questions use the word "spiritual" literally and some of these questions also do not ask about firsthand experiences. For example, "To what extent does any connection to a spiritual being help you to understand others?" Some items include a hidden contingency, for example "How satisfied are you that you have a balance between mind, body and soul?"

Confusion with Well-Being Items ask about positive affect. Several items ask whether the connection to a spiritual being, faith or spiritual strength helps to feel happy or gives comfort. The questionnaire is therefore unsuitable for determining the relationship between spirituality and well-being.

\section{Discussion}

Multidimensional spirituality questionnaires are preferred above one- or two-dimensional questionnaires if one tries to answer specific questions such as "Which aspects of spirituality are most important in the process of adjusting to a chronic or life-threatening disease?" or "Which aspect changes most as a consequence of being exposed to a stressor?"

The SWBQ and the STS have the best psychometric qualities. The SWBQ has been investigated in detail in student populations, but its validity is still to be proven in a sample of the general population. The psychometric characteristics of the STS have been studied sufficiently and appeared to be acceptable, except for the Connectedness subscale.

Only the SWBQ consists of appropriate items that inquire about firsthand experiences, ask one question at a time and have a consistent meaning.

All questionnaires, except the WHOQOL SRPB, can be used to study the relationship between spirituality and well-being/distress, as they do not directly inquire about positive or negative affect.

If one applied all our criteria, the Spiritual Well-being Questionnaire (SWBQ) of Gomez and Fisher (2003) proves most promising. Although as mentioned elsewhere, its reliability and validity are still to be proven in a population sample.

\section{General Discussion}

In this review, we focused on the relatively few spirituality questionnaires that measure spirituality as an experience or attitude that transcends any particular religion. These questionnaires have the advantage that they can be used among people who adhere to a faith or no faith at all. In nursing and health studies, these questionnaires are indispensable as researchers generally do not want to exclude people on the basis of their religious background. Questionnaires were only included in this review if they contained none or a 
limited number of religious or belief items. Questionnaires were allowed to have a maximum of one religious subscale. Popular spirituality questionnaires such as the Daily Spiritual Experience Scale (DSE; Underwood and Teresi 2002), the Index of Core Spiritual Experience (INSPIRIT; Kass et al. 1991) and the Brief Multidimensional Measure of Religiousness/Spirituality, Fetzer Institute/NIA (BMMRS; Fetzer Institute 1999; Idler et al. 2003) were therefore not included. These questionnaires contain many items that assume that the respondent believes in God, as illustrated in items such as "I feel God's love for me, through others" (DSES) and "I work together with God as partners" (BMMRS). These questionnaires might be applicable in the USA, because its inhabitants are predominantly religious, but applicability of such scales in a society less grounded in a monotheistic tradition is doubtful. Some questionnaires do not contain items about God but instead ask about other kinds of belief. The Spiritual Orientation Inventory (SOI; Elkins et al. 1988) is an example of such a questionnaire. Examples of its items are "The universe is not yet done but is unfolding in a meaningful way" and "Humans are sometimes "called" to fulfill a certain spiritual destiny". In our opinion, people with certain beliefs are not necessarily more spiritual than people without these beliefs. The questionnaires in this review instead refer to universal experiences and attitudes, such as connectedness with nature, compassion, gratitude, mystical experiences and self-actualization.

The quality of the spirituality questionnaires appeared to be low. We may seem overcritical, but the NIA/Fetzer panel that has reviewed more than 200 religiosity and spirituality measures, reached a similar conclusion (George et al. 2000).

One flaw in most scales is that the psychometric evaluation is limited or unsatisfactory. Most questionnaires are not factor-analyzed or the factor solutions appeared inconsistent. In addition, information about convergent validity is lacking for most multidimensional questionnaires. Information about discriminant validity and about the association between the subscales was so often lacking that we chose not to include these validation types as formal criteria. Future research, however, should also pay attention to these forms of validation, as they are important in the delineation of the construct of spirituality. Theoretically proposed spirituality facets should be highly related to each other as they all are indicators of the same construct. Furthermore, spiritual facets should be discriminated from other psychological constructs such as well-being, social support, or personality factors. It is encouraging that some evidence was found for the delineation of the construct. For example, the four subscales of the SWBQ could be discriminated from personality factors and social desirability, and a single underlying factor was found for the four dimensions.

A second flaw is that most questionnaires use inappropriate questions. Particularly, the criterion of having a consistent meaning was often unmet. In several questionnaires, this criterion was unmet because words such as spirit or spirituality were often used. The item of the SIBS-R "I have been through a time of suffering that led to spiritual growth", for example, will be answered affirmatively by a person who interprets the word spirituality in a positive way, referring to living in accordance with one's values and involvement in society. Another person may answer the question negatively, because he or she is not familiar with the term or has a negative association. Consequently, two respondents that have had the same experience could possibly give contrary answers. Inconsistent meaning of items was also often the result of using metaphors or abstract concepts, e.g. "I have the ability to rise above or beyond a physical or psychological condition" (SAS), "The death means returning "home"" (PSQ), or "There is an order to the universe that transcends human thinking" (STS of (Piedmont 1999).

A third conceptual flaw is the inclusion of well-being items in scales that are sometimes described as "spiritual well-being" scales. Therefore, to avoid tautology when 
investigating the relationship with well-being, we advise against four questionnaires (FACIT-sp12, STS, Reed 1991, SWB and WHOQOL-SRPB).

In summary, this paper presents a critical discussion on a selection of questionnaires that can be used to assess spirituality as a universal phenomenon. Four global and six multidimensional questionnaires were evaluated. None of the questionnaires fulfilled all our criteria. Only the multidimensional Spiritual Well-being Questionnaire (SWBQ) from Gomez and Fisher (2003) is promising. Its validity and reliability have been proven in student samples, most items are appropriately formulated, and it does not include wellbeing items. In addition, the questionnaire consists of only twenty short items and will therefore easily be administrated in clinical nursing samples. With the SWBQ, scholars can investigate whether a spiritual orientation can help people to cope with the consequences of a serious disease, without excluding people on the basis of their religious background.

Acknowledgments This study was funded by the Dutch Cancer Society. Grant number: HDI 2004-3177.

Open Access This article is distributed under the terms of the Creative Commons Attribution Noncommercial License which permits any noncommercial use, distribution, and reproduction in any medium, provided the original author(s) and source are credited.

\section{References}

Baldacchino, D., \& Draper, P. (2001). Spiritual coping strategies: A review of the nursing research literature. Journal of Advanced Nursing, 34, 833-841.

Bartlett, S. J., Matsumoto, A. K., Bathon, J. M., Piedmont, R., \& Bilderback, A. (2003). Spirituality, wellbeing, and quality of life in people with rheumatoid arthritis. Arthritis and Rheumatism, 49, 778-783.

Brady, M. J., Peterman, A. H., Fitchett, G., Mo, M., \& Cella, D. (1999). A case for including spirituality in quality of life measurement in oncology. Psycho-Oncology, 8, 417-428.

Carballo, M. (1999). Religion in the world at the end of the millennium. Retrieved March 15, 2005, from http://www.gallup-international.com.

Carson, V. B., Soeken, K. L., Shanty, J., \& Toms, L. (1990). Hope and spiritual well-being: Essentials for living with AIDS. Perspectives in Psychiatric Care, 26, 28-34.

Chin, A. L., \& Fernsler, J. I. (1998). Self-transcendence in older men attending a prostate cancer support group. Cancer Nursing, 21, 358-363.

Chiu, L., Emblen, J. D., Van Hofwegen, L., Sawatzky, R., \& Meyerhoff, H. (2004). An integrative review of the concept of spirituality in the health sciences. Western Journal of Nursing Research, 26, 405-428.

Cohen, J. (1988). Statistical power analysis for the behavioral sciences (2nd ed.). Hillsdale, NJ: Lawrence Erlbaum Associates.

Cook, C. C. H. (2004). Addiction and spirituality. Addiction, 99, 539-551.

Coward, D. D. (1996). Self-transcendence and correlates in a healthy population. Nursing Research, 45, 116-121.

Dyson, J., Cobb, M., \& Forman, D. (1997). The meaning of spirituality: A literature review. Journal of Advanced Nursing, 26, 1183-1188.

Egbert, N., Mickley, J., \& Coeling, H. (2004). A review and application of social scientific measures of religiosity and spirituality: Assessing a missing component in health communication research. Health Communication, 16, 7-27.

Elkins, D. N., Hedstrom, L. J., Hughes, L. L., Leaf, J. A., \& Saunders, C. (1988). Toward a humanistic phenomenological spirituality. Definition, description, and measurement. Journal of Humanistic Psychology, 28, 5-18.

Ellermann, C. R., \& Reed, P. G. (2001). Self-transcendence and depression in middle-age adults. Western Journal of Nursing Research, 23, 698-713.

Ellis, J. B., \& Smith, P. C. (1991). Spiritual well-being, social desirability and reasons for living: is there a connection? International Journal of Social Psychiatry, 37, 57-63.

Ellison, C. W. (1983). Spiritual well-being: Conceptualization and measurement. Journal of Psychology and Theology, 11, 330-340. 
Fetzer Institute. (1999). Multidimensional measurement of religiousness/spirituality for use in health research. A report of the Fetzer Institute/National Institute on Aging Working Group. Kalamazoo: Fetzer Institute.

Fisher, J. W. (1998). Spiritual health: its nature, and place in the school curriculum. Melbourne, VIC, Australia: The University of Melbourne.

Fowler, F. J. (1995). Improving Survey Questions - design and evaluation. Applied Social Research Methods (Vol. 38). London: Sage Publications.

Garssen, B., Dierendonck, D. v., \& Tromp, S. (2001). Meten van spirituele ervaringen. Aspecten van en vragenlijsten over spiritualiteit. Gedrag en Gezondheid, 29, 211-227.

George, L. K., Larson, D. B., Koenig, H. G., \& McCullough, M. E. (2000). Spirituality and health: What we know, what we need to know. Journal of Social and Clinical Psychology, 19, 102-116.

Gomez, R., \& Fisher, J. W. (2003). Domains of spiritual well-being and development and validation of the spiritual well-being questionnaire. Personality and Individual Differences, 35, 1975-1991.

Gomez, R., \& Fisher, J. W. (2005a). Item response theory analysis of the spiritual well-being questionnaire. Personality and Individual Differences, 38, 1107-1121.

Gomez, R., \& Fisher, J. W. (2005b). The spiritual well-being questionnaire: Testing for model applicability, measurement and structural equivalencies, and latent mean differences across gender. Personality and Individual Differences, 39, 1383-1393.

Hatch, R. L., Burg, M. A., Naberhaus, D. S., \& Hellmich, L. K. (1998). The spiritual involvement and beliefs scale. Development and testing of a new instrument. Journal of Family Practice, 46, 476-486.

Heelas, P. (2000). Expressive spirituality and humanistic expressivism: Sources of significance beyond church and chapel. In S. Sutcliffe \& M. Bowman (Eds.), Beyond new age. Exploring alternative spirituality (pp. 237-254).

Heelas, P. (2005). The spiritual revolution: Why religion is giving way to spirituality. Malden: Blackwell.

Hill, P. C. (2005). Measurement in the psychology of religion and spirituality: Current status and evaluation. In R. F. Paloutzian \& C. L. Park (Eds.), Handbook of the psychology of religion and spirituality (pp. 43-61). London: The Guilford Press.

Hill, P. C., \& Hood, R. W. (1999). Measures of religiosity. Birmingham, AL: Religious Education Press.

Hill, P. C., Pargament, K. I., Hood, R. W., McCullough, M. E., Swyers, J. P., Larson, D. B., et al. (2000). Conceptualizing religion and spirituality: Points of commonality, points of departure. Journal for the Theory of Social Behaviour, 30, 51-77.

Hood, R. W. (1975). The construction and preliminary validation of a measure of reported mystical experience. Journal for the Scientific Study of Religion, 14, 29-41.

Howden, J. W. (1992). Development and psychometric characteristics of the spirituality assessment scale. Ann Arbor: Texas Woman's University, UMI Dissertation Services.

Hungelmann, J. A., Kenkel-Rossi, E., Klassen, L., \& Stollenwerk, R. M. (1985). Spiritual well-being in older adults: Harmonious interconnectedness. Journal of Religion and Health, 24, 147-153.

Hyland, M. E., Whalley, B., \& Geraghty, A. W. A. (2007). Dispositional predictors of placebo responding: A motivational interpretation of flower essence and gratitude therapy. Journal of Psychosomatic Research, 62, 331-340.

Idler, E. L., Musick, M. A., Ellison, C. G., George, L. K., Krause, N., Ory, M. G., et al. (2003). Measuring multiple dimensions of religion and spirituality or health research-conceptual background and findings from the 1998 General Social Survey. Research on Aging, 25, 327-365.

Kass, J. D., Friedman, R., Leserman, J., Zuttermeister, P. C., \& Benson, H. (1991). Health outcomes and a new index of spiritual experience. Journal for the Scientific Study of Religion, 30, 203-211.

King, J. E., \& Crowther, M. R. (2004). The measurement of religiosity and spirituality: Examples and issues from psychology. Journal of Organizational Change Management, 17, 83-101.

Koenig, H. G., McCullough, M. E., \& Larson, D. B. (2001). Handbook of religion and health. New York: University Press.

Leach, M. M., \& Lark, R. (2004). Does spirituality add to personality in the study of trait forgiveness? Personality and Individual Differences, 37, 147-156.

Ledbetter, M. F., Smith, L. A., Fischer, J. D., Vosler-Hunter, W. L., \& Chew, G. P. (1991a). An evaluation of the construct validity of the spiritual well-being scale: a confirmatory factor analytic approach. Journal of Psychology and Theology, 19, 94-102.

Ledbetter, M. F., Smith, L. A., Fischer, J. D., Vosler-Hunter, W. L., \& Fischer, J. D. (1991b). An evaluation of the research and clinical usefulness of the spiritual well-being scale. Journal of Psychology and Theology, 19, 49-55.

Leung, K. K., Chiu, T. Y., \& Chen, C. Y. (2006). The influence of awareness of terminal condition on spiritual well-being in terminal cancer patients. Journal of Pain and Symptom Management, 31, $449-456$. 
Lukoff, D., Turner, R., \& Lu, F. G. (1993). Transpersonal psychology research review: psychospiritual dimensions of healing. Journal of Transpersonal Psychology, 25, 11-28.

MacDonald, D. A. (2000). Spirituality: Description, measurement, and relation to the five factor model of personality. Journal of Personality, 68, 153-197.

MacDonald, D. A., Friedman, H. L., \& Kuentzel, J. G. (1999a). A survey of measures of spiritual and transpersonal constructs: Part one-research update. Journal of Transpersonal Psychology, 31, $137-154$.

MacDonald, D. A., Kuentzel, J. G., \& Friedman, H. L. (1999b). A survey of measures of spiritual and transpersonal constructs: Part two-additional instruments. Journal of Transpersonal Psychology, 31, 155-178.

MacDonald, D. A., LeClair, L., Holland, C. J., Alter, A., \& Friedman, H. L. (1995). A survey of measures of transpersonal constructs. Journal of Transpersonal Psychology, 27, 171-235.

Mahoney, M. J., \& Graci, G. M. (1999). The meanings and correlates of spirituality: Suggestions from an exploratory survey of experts. Death Studies, 23, 521-528.

Matheis, E. N., Tulsky, D. S., \& Matheis, R. J. (2006). The relation between spirituality and quality of life among individuals with spinal cord injury. Rehabilitation Psychology, 51, 256-271.

McSherry, W., \& Cash, K. (2004). The language of spirituality: an emerging taxonomy. International Journal of Nursing Studies, 41, 151-161.

Miller, G., Fleming, W., \& Brown-Anderson, F. (1998). Spiritual well-being scale ethnic differences between Caucasians and African-Americans. Journal of Psychology and Theology, 26, 358-364.

Miller, W. R., \& Thoresen, C. E. (2003). Spirituality, religion, and health-an emerging research field. American Psychologist, 58, 24-35.

Moberg, D. O. (2002). Assessing and measuring spirituality: Confronting dilemmas of universal and particular evaluative criteria. Journal of Adult Development, 9, 47-60.

Muldoon, M., \& King, N. (1995). Spirituality, health care, and bioethics. Journal of Religion and Health, 34, 329-349.

Murray, R. B., \& Zenter, J. B. (1989). Nursing concepts for health promotion. London: Prentice-Hall.

National Interfaith Coalition on Aging. (1975). Spiritual well-being: a definition. Athens, GA: National Interfaith Coalition on Aging.

Noguchi, W., Morita, S., Ohno, T., Aihara, O., Tsujii, H., Shimozuma, K., et al. (2006). Spiritual needs in cancer patients and spiritual care based on logotherapy. Supportive Care in Cancer, 14, 65-70.

Noguchi, W., Ohno, T., Morita, S., Aihara, O., Tsujii, H., Shimozuma, K., et al. (2004). Reliability and validity of the Functional Assessment of Chronic Illness Therapy-Spiritual (FACIT-Sp) for Japanese patients with cancer. Supportive Care in Cancer, 12, 240-245.

Nygren, B., Alex, L., Jonsen, E., Gustafson, Y., Norberg, A., \& Lundman, B. (2005). Resilience, sense of coherence, purpose in life and self-transcendence in relation to perceived physical and mental health among the oldest old. Aging \& Mental Health, 9, 354-362.

O'Connell, K. A., Saxena, S., \& Underwood, L. (2006). A cross-cultural study of spirituality, religion, and personal beliefs as components of quality of life. Social Science and Medicine, 62, 1486-1497.

Peterman, A. H., Fitchett, G., Brady, M. J., Hernandez, L., \& Cella, D. (2002). Measuring spiritual wellbeing in people with cancer: The functional assessment of chronic illness therapy-spiritual well-being scale (FACIT-Sp). Annals of Behavioral Medicine, 24, 49-58.

Piedmont, R. L. (1999). Does spirituality represent the sixth factor of personality? Spiritual transcendence and the five-factor model. Journal of Personality, 67, 985-1013.

Piedmont, R. L. (2001). Spiritual transcendence and the scientific study of spirituality. Journal of Rehabilitation, 67, 4-14.

Piedmont, R. L. (2004). Spiritual transcendence as a predictor of psychosocial outcome from an outpatient substance abuse program. Psychology of Addictive Behaviors: Journal of the Society of Psychologists in Addictive Behaviors, 18, 213-222.

Piedmont, R. L., \& Leach, M. M. (2002). Cross-cultural generalizability of the spiritual transcendence scale in India-spirituality as a universal aspect of human experience. American Behavioral Scientist, 45, 1888-1901.

Reed, P. G. (1991). Self-transcendence and mental-health in oldest-old adults. Nursing Research, 40, 5-11.

Reed, P. G. (1992). An emerging paradigm for the investigation of spirituality in nursing. Research in Nursing and Health, 15, 349-357.

Rican, P., \& Janosova, P. (2005). Spirituality: its psychological operationalization via measurement of individual differences: A Czech perspective. Studia Psychologica, 47, 157-165.

Riley, B. B., Perna, R., Tate, D., Forchheimer, M., Anderson, C., \& Luera, G. L. (1998). Types of spiritual well-being among persons with chronic illness: Their relation to various forms of quality of life. Archives of Physical Medicine and Rehabilitation, 79, 258-264. 
Sawatzky, R., Ratner, P. A., \& Chiu, L. (2005). A meta-analysis of the relationship between spirituality and quality of life. Social Indicators Research, 72, 153-188.

Scott, E. L., Agresti, A. A., \& Fitchett, G. (1998). Factor analysis of the 'spiritual well-being scale' and its clinical utility with psychiatric inpatients. Journal for the Scientific Study of Religion, 37, 314-321.

Shorkey, C., Uebel, M., \& Windsor, L. C. (2007). Measuring dimensions of spirituality in chemical dependence treatment and recovery: research and practice. International Journal of Mental Health and Addiction. Published online October 13, 2007, http://www.springerlink.com/content/132u40081 22x0732/.

Smith, T. B., McCullough, M. E., \& Poll, J. (2003). Religiousness and depression: Evidence for a main effect and the moderating influence of stressful life events. Psychological Bulletin, 129, 614-636.

Stanard, R. P., Sandhu, D. S., \& Painter, L. C. (2000). Assessment of spirituality in counselling. Journal of Counseling and Development, 78, 204-210.

Stefanek, M., McDonald, P. G., \& Hess, S. A. (2005). Religion, spirituality and cancer: Current status and methodological challenges. Psycho-Oncology, 14, 450-463.

Tuck, I., mcCain, N. L., \& Elswick, R. K. (2001). Spirituality and psychosocial factors in persons living with HIV. Journal of Advanced Nursing, 33, 776-783.

Underwood, L. G., \& Teresi, J. A. (2002). The daily spiritual experience scale: Development, theoretical description, reliability, exploratory factor analysis, and preliminary construct validity using healthrelated data. Annals of Behavioral Medicine, 24, 22-33.

Vaughan, F. (1991). Spiritual issues in psychotherapy. Journal of Transpersonal Psychology, 23, 105-119.

Vella-Brodrick, D. A., \& Allen, F. C. L. (1995). Development and psychometric validation of the mental, physical, and spiritual well-being scale. Psychological Reports, 77, 659-674.

Vellabrodrick, D. A., \& White, V. (1997). Response set of social desirability in relation to the mental, physical and spiritual well-being scale. Psychological Reports, 81, 127-130.

Wasner, M., Longaker, C., Fegg, M. J., \& Borasio, G. D. (2005). Effects of spiritual care training for palliative care professionals. Palliative Medicine, 19, 99-104.

Weaver, A. J., Pargament, K. I., Flannelly, K. J., \& Oppenheimer, J. E. (2006). Trends in the scientific study of religion, spirituality, and health: 1965-2000. Journal of Religion and Health, 45, 208-214.

WHOQOL Group. (1996). What is quality of life? The World Health Organization Quality of Life Assessment. World Health Forum, 17, 354-356.

Young-Eisendrath, P., \& Miller, M. E. (2000). Beyond enlightened self-interest: The psychology of mature spirituality in the twenty-first century. In P. Young-Eisendrath \& M. E. Miller (Eds.), The psychology of mature spirituality. Integrity, wisdom, transcendence (pp. 1-7). London: Routledge.

Zinnbauer, B. J., Pargament, K. I., \& Scott, A. B. (1999). The emerging meanings of religiousness and spirituality: Problems and prospects. Journal of Personality, 67, 889-919. 